Article

\title{
Pre-Concentration of Iron-Rich Sphalerite by Magnetic Separation
}

\author{
Soobok Jeong and Kwanho Kim * \\ DMR Convergence Research Center, Korea Institute of Geoscience and Mineral Resources, Daejeon 34132, Korea; \\ sbjeong@kigam.re.kr \\ * Correspondence: khkim@kigam.re.kr; Tel.: +82-42-868-3580
}

Received: 9 May 2018; Accepted: 25 June 2018; Published: 27 June 2018

\begin{abstract}
With the rise in metal prices and the growing importance of metallic minerals in the South Korean economy, there has been a steadily increasing demand to redevelop metal mines that have been shut down since the 1990s. However, it is not possible to ensure that such plans are economically feasible by using conventional mining processes, mainly flotation, because of low ore grade and complex mineral compositions. To improve the efficiency, and to reduce the operating cost of the entire process, pre-concentration by magnetic separation of $\mathrm{Pb}-\mathrm{Zn}$ deposits has been investigated to reduce the mass and improve the grade of feed samples that are loaded into the flotation system. The results show that the response of sphalerite to magnetic separation varied as a function of its iron content: iron-rich sphalerite was recovered at magnetic intensities below $0.65 \mathrm{~T}$, and relatively pure sphalerite was recovered at magnetic intensities above $0.85 \mathrm{~T}$. Therefore, $\mathrm{Pb}-\mathrm{Zn}$ ore could be sufficiently pre-concentrated by magnetic separation between 0.65 and $0.85 \mathrm{~T}$ to remove low-grade target elements. As a result, the mass of the sample fed into the flotation system was reduced almost by half, and the grade of zinc, lead, and copper was enhanced by $65 \%, 55 \%$, and $33 \%$, respectively. Therefore, it is possible to improve the efficiency of the entire process by reducing the amount of the sample to be fed to subsequent processes, such as grinding and flotation, while minimizing loss of the target mineral through magnetic separation.
\end{abstract}

Keywords: sphalerite; $\mathrm{Pb}-\mathrm{Zn}$ deposit; magnetic separation; beneficiation; pre-concentration

\section{Introduction}

In South Korea, approximately forty domestic metallic mineral mines were in active operation until the 1980s. Nine of these mines were dedicated to the mining of $\mathrm{Pb}-\mathrm{Zn}$ deposits, including the Gagok mine. All mineral processing circuits consisted of crushing, grinding, and flotation, which were not significantly different from those of $\mathrm{Pb}-\mathrm{Zn}$ mines in the rest of the world [1-3]. However, ores in South Korean metal mines consist of complex metallic minerals and have various impurities. In particular, the deposits in the Gagok mine contain various sulfide minerals, such as zinc sulfide, lead sulfide, and copper sulfide, and the zinc sulfide mineral, known as sphalerite, contains an especially high amount of iron as an impurity. As the quality of extracted ores and the related profitability gradually deteriorated, the operators started to close the metal mines in the 1990s.

Sphalerite $(\mathrm{ZnS})$ is a representative zinc-containing sulfide mineral, and it is the most important resource for zinc metal production. Sphalerite is normally found with other sulfide minerals such as galena, chalcopyrite, and pyrite in $\mathrm{Pb}-\mathrm{Zn}$ deposits, and they are separated from each other by froth flotation [3-5]. Therefore, for many decades, many researchers have focused on the flotation behavior of sphalerite when it is separated from other sulfide minerals [2,6-9]. Recent studies also investigated copper activation and depression of sphalerite with various other sulfide minerals for selective flotation. The adsorption of cupric ions from a solution on the mineral surface for activating 
sphalerite depends on various factors, such as copper concentration, activation time, pulp potential, and galvanic interaction [10-14]. The effect of sphalerite depression using various reagents was investigated to float other sulfide minerals separately [15-17]. However, some studies reported that when sphalerite contains iron as an impurity, the adsorption of cupric ions on the sphalerite surface decreases with increasing iron content, leading to a low recovery of the mineral [18-20].

The chemical composition of sphalerite depends on the origin and area of ore deposits, and pure sphalerite rarely exists in nature because it invariably contains various impurities, with iron being the most abundant. When the iron content is more than about $10 \%$, the zinc sulfide mineral is referred to as marmatite $\left(\mathrm{Zn}_{x} \mathrm{Fe}_{1-x} \mathrm{~S}\right)$, and the physical and electrochemical properties of sphalerite are known to vary with the iron content [21]. Among various properties of iron-containing sphalerite, the most representative feature is the magnetic susceptibility. According to previous studies on the magnetic susceptibility of sulfide minerals, sphalerite is a diamagnetic mineral in the pure state, and it becomes a paramagnetic mineral upon the addition of elemental iron; in other words, the magnetic susceptibility of sphalerite increases as the iron content increases in a sample [22-25]. However, there have not been many studies on the magnetic properties of iron-rich sphalerite, and it is not easy to find information on the actual beneficiation process of the sulfide mineral.

As metal prices increase and metallic minerals play an increasingly important role in the South Korean economy, various efforts and attempts have been made to redevelop closed mines. However, if previously used conventional processes are applied, it is very likely that the same problems that caused the mines' demise will emerge again. Therefore, an additional or enhanced process that can improve the efficiency and economy of the entire process should be developed. In this study, gravity separation and magnetic separation were investigated as possible means to pre-concentrate iron-rich sphalerite in $\mathrm{Pb}-\mathrm{Zn}$ deposits and reduce the mass fraction introduced to the flotation process. If the mass fraction loaded to the flotation process is successfully reduced by pre-concentration, several advantages can be expected, such as the reduction of grinding cost, reagent consumption, wastewater treatment cost, and tailing treatment cost.

\section{Materials and Methods}

\subsection{Material}

The sample used in this study was a $\mathrm{Pb}-\mathrm{Zn}$ deposit obtained from the Gagok mine in South Korea. The Gagok mine is one of the metal mines in the Mount Taebaek mining district and the second largest $\mathrm{Pb}-\mathrm{Zn}$ mine in the country. According to a previous geological study [26], about 600,000 tons of ore were produced in 1978, and the average grades of zinc, lead, and copper were $3.9 \%, 0.2 \%$, and $0.1 \%$, respectively. This mine has been in a state of temporary shutdown since 1987, and a feasibility test is being planned to re-open the site for active operation.

For the feasibility test, samples were obtained at various places on separate occasions, and they were mixed repeatedly to form a representative sample. This feed sample was used for the pre-concentration study presented here. The feed sample was crushed by a jaw crusher (JS-1, Jung Sin, Pohang, Korea) and a cone crusher (Marcy 10", Svedala, Danville, PA, USA) for mineralogy and chemical composition analysis using X-ray diffraction (XRD; D/Max-2500, Rigaku, Tokyo, Japan), optical microscopy (CS-300, Leica, Wetzlar, Germany), scanning electron microscopy-energy-dispersive X-ray spectroscopy (SEM-EDS; JSM-6390, JEOL, Tokyo, Japan; 51-ADD0002, Oxford Instruments, Abingdon, UK), and inductive coupled plasma-optical emission spectrometry (ICP-OES; Optima-5300 DV, PerkinElmer, Waltham, MA, USA). For mineralogy analysis, the feed sample was first analyzed by optical microscopy and XRD. The type and condition of the constituent minerals were confirmed by optical microscopy and XRD, and the results were used as basic data to develop the beneficiation process. After confirming the target and gangue minerals, basic separation tests were conducted using gravitational and magnetic separation methods to concentrate the target minerals. 


\subsection{Methods}

To recover high-density metallic minerals, a shaking table (No. 13 Wilfley table, Humphreys, Jacksonville, FL, USA) was used for gravity separation. The operating conditions were adjusted based on the general conditions under which the equipment was operated. The angle of the shaking table, shaking amplitude, and water flowrate were varied from $1^{\circ}$ to $5^{\circ}$, from 10 to $20 \mathrm{~mm}$, and from 8 to $12 \mathrm{~L} / \mathrm{min}$, respectively. However, the frequency was fixed at $300 \mathrm{rpm}$ owing to the fixed motor speed and reduction gear ratio. Under various operating conditions, the optimum conditions for the best separation efficiency were determined as follows: the angle of the shaking table was $2.5^{\circ}$, shaking amplitude was $15 \mathrm{~mm}$, and water flowrate was $10 \mathrm{~L} / \mathrm{min}$. The results of the shaking table experiment were divided into four categories - concentration, middling, tailing, and slime-according to the area in which the sample was recovered in the top-view of shaking table, as shown in Figure 1.

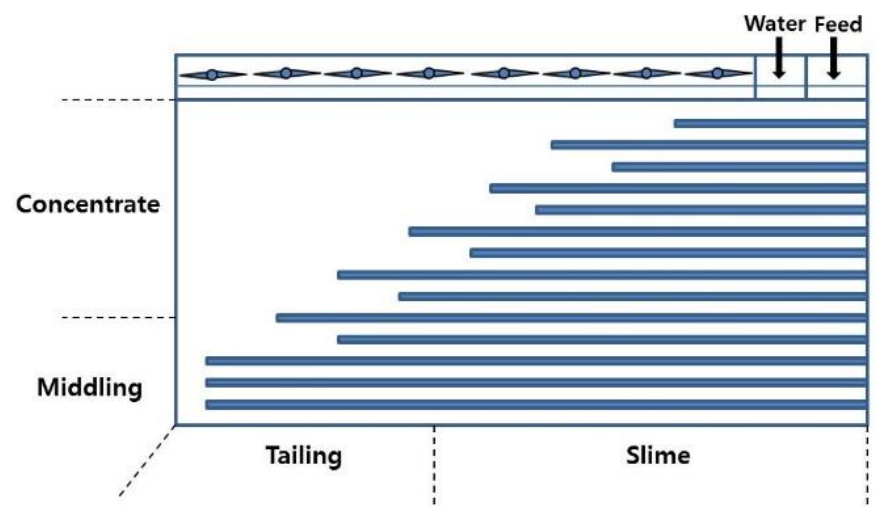

Figure 1. Categories of recovered samples in shaking table experiment.

In the magnetic separation process, a laboratory-scale cross-belt-type magnetic separator (CBMS; Model EE112, Eriez, Erie, PA, USA) was employed to recover the magnetic minerals. By changing the current supplied to the separator, the applied magnetic field was modulated between 0.2 and $1.4 \mathrm{~T}$. The magnetic separation tests were conducted as the magnetic intensity was increased from an initial low value of $0.2 \mathrm{~T}$. After separation of the magnetic products at low intensity, the remaining sample was fed into a magnetic separator adjusted to a slightly higher magnetic intensity to conduct further separation tests. The magnetic separation tests were carried out sequentially in this manner until the magnetic intensity reached $1.4 \mathrm{~T}$.

The threshold particle size for magnetic separation was varied between 0.3 to $2 \mathrm{~mm}$ to determine the appropriate particle size for magnetic separation. Although a smaller particle size generally improves the degree of liberation, excessively fine particles can deteriorate the separation efficiency in magnetic separation. Moreover, an appropriate particle size can reduce the operating cost resulting from over-grinding.

A total of $10 \mathrm{~kg}$ of the feed sample was processed, and the results were confirmed to verify that the sample was successfully pre-concentrated in the magnetic separation process.

\section{Results and Discussion}

\subsection{Chemical Composition of Feed Sample}

The XRD pattern of the feed sample in Figure 2 reveals that sphalerite was the major sulfide mineral, and quartz, calcite, and muscovite were the major gangue minerals. However, galena and chalcopyrite, which usually accompany sphalerite in $\mathrm{Pb}-\mathrm{Zn}$ deposits, were not detected by XRD owing to their low content, as shown in Table 1. Table 1 also shows the concentration (wt \%) of target elements as a function of particle size in the feed sample. The concentration of zinc in the entire sample was $4.88 \mathrm{wt} \%$, and the lead and copper concentrations were both $0.09 \mathrm{wt} \%$, which are much lower than 
the zinc concentration. Therefore, the concentration of zinc, the main element in sphalerite, was the main consideration for the pre-concentration test. Theoretically, iron in sphalerite can be accompanied by zinc, and when the iron content is higher than $10 \mathrm{wt} \%$, it has an opaque black appearance and is called marmatite. The high iron content $(15.3 \mathrm{wt} \%$ ) of the feed sample (Table 1) can be attributed to the high iron content of marmatite or the presence of other iron-bearing minerals. The concentrations of the target elements—zinc, lead, and copper-gradually increased as the particle size decreased. As a result, the total concentration of target elements in particles with sizes below $74 \mu \mathrm{m}$ was higher than that in the entire feed sample, probably due to the breakage property of metallic minerals. Normally, pure metallic minerals tend to be brittle, and fine particles are easily produced when they break. In our study, breakage of the minerals accounted for the high concentration of target elements in fine particles with sizes below $74 \mu \mathrm{m}$.

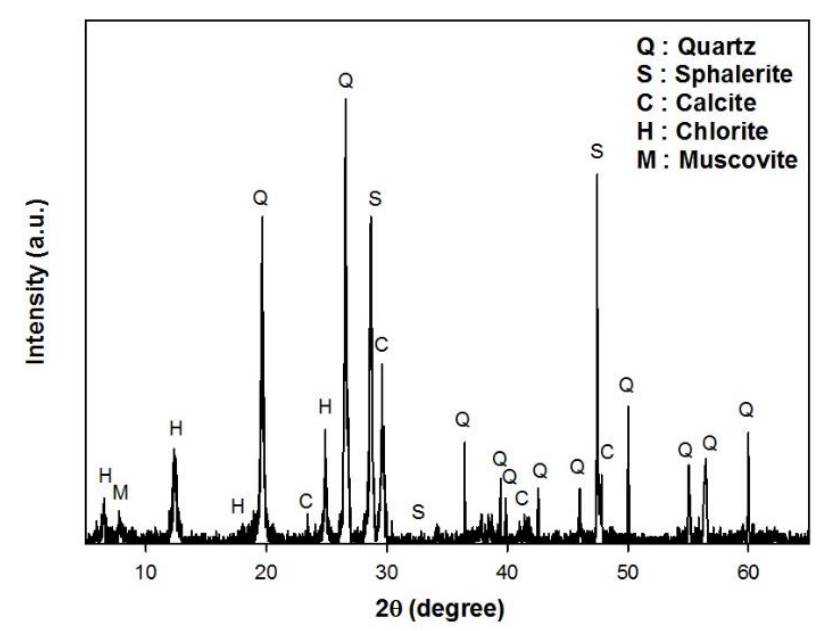

Figure 2. X-ray diffraction (XRD) pattern of the feed sample.

Table 1. Yield (wt \%) and concentration ( $w t \%$ ) of the target elements in the feed sample as a function of size fractions.

\begin{tabular}{cccccc}
\hline \multirow{2}{*}{ Size Fraction } & \multirow{2}{*}{$\begin{array}{c}\text { Yield } \\
\mathbf{( w t} \mathbf{\%})\end{array}$} & \multicolumn{4}{c}{ Concentration (wt \%) } \\
\cline { 3 - 6 } & & Fe & $\mathbf{Z n}$ & $\mathbf{P b}$ & $\mathbf{C u}$ \\
\hline$>212 \mu \mathrm{m}$ & 12.5 & 14.6 & 2.90 & 0.05 & 0.06 \\
$106-212 \mu \mathrm{m}$ & 16.0 & 15.0 & 3.62 & 0.06 & 0.07 \\
$74-106 \mu \mathrm{m}$ & 21.6 & 15.6 & 4.92 & 0.06 & 0.08 \\
$37-74 \mu \mathrm{m}$ & 13.1 & 16.1 & 5.69 & 0.10 & 0.10 \\
$<37 \mu \mathrm{m}$ & 36.8 & 15.3 & 5.79 & 0.13 & 0.11 \\
Total & 100.0 & 15.3 & 4.88 & 0.09 & 0.09 \\
\hline
\end{tabular}

\subsection{Microscope Analysis of Feed Sample}

To determine the presence of not only major target minerals, but also trace minerals that were not detected by XRD analysis, the feed sample was analyzed by microscopy. Table 2 shows the result of traditional modal analysis of 10 thin sections of the feed sample. Modal analysis is normally used in geology to estimate the relative proportions of different minerals from microscope images, and the proportion of each mineral is defined as the ratio of area occupied by a particular mineral to the area occupied by all minerals. For our feed sample, sphalerite was the most abundant target mineral, and its area proportion was approximately $5-20 \%$ of the total area in various thin sections. Small amounts $(\approx 1 \%)$ of chalcopyrite and galena were identified as the trace target minerals. Pyrrhotite and pyrite were identified as the iron-bearing minerals, which accounted for the high iron content in the feed sample. 
Table 2. Area proportion (\%) of each mineral identified by modal analysis of microscope images of the feed sample.

\begin{tabular}{ccccccccccc}
\hline Mineral & $\mathbf{1}$ & $\mathbf{2}$ & $\mathbf{3}$ & $\mathbf{4}$ & $\mathbf{5}$ & $\mathbf{6}$ & $\mathbf{7}$ & $\mathbf{8}$ & $\mathbf{9}$ & $\mathbf{1 0}$ \\
\hline Sphalerite & 14 & 15 & 17 & 7 & 20 & - & 18 & 20 & 5 & 8 \\
Chalcopyrite & $<0.5$ & 1 & 1 & 1 & 1 & 1 & 1 & $<0.5$ & $<0.5$ & $<0.5$ \\
Galena & $<0.5$ & - & - & - & $<0.5$ & - & - & - & - & 1 \\
Pyrrhotite & $<0.5$ & 16 & 18 & 8 & 3 & 9 & 16 & $<0.5$ & 3 & $<0.5$ \\
Pyrite & $<0.5$ & 1 & 3 & 2 & $<0.5$ & $<0.5$ & 2 & 2 & $<0.5$ & 30 \\
Marcasite & - & 1 & 1 & 1 & - & & 2 & - & - & - \\
Magnetite & - & - & - & 1 & - & - & - & - & - & - \\
Pb-Bi-S & - & $<0.5$ & $<0.5$ & - & - & - & $<0.5$ & - & - & - \\
Ilmenite & $<0.5$ & - & - & - & - & - & - & - & - & - \\
Pyroxenes & 1 & 56 & 46 & 58 & 37 & 61 & 22 & 62 & 88 & 34 \\
Garnet & - & - & - & - & 22 & - & 13 & - & - & 2 \\
Amphiboles & 7 & - & 2 & 3 & $<0.5$ & 12 & 1 & - & $<0.5$ & 2 \\
Calcite & 32 & $<0.5$ & 5 & 11 & 8 & 6 & 9 & $<0.5$ & - & 10 \\
Epidote & - & - & - & - & - & - & 3 & 12 & 1 & - \\
Quartz & 36 & - & - & 2 & 1 & $<0.5$ & $<0.5$ & - & - & 2 \\
Biotite & 7 & 5 & 4 & 4 & 4 & 4 & 4 & $<0.5$ & - & 3 \\
Fluorite & - & - & - & - & - & - & 5 & - & - & - \\
\hline
\end{tabular}

Figure 3 shows images of various ore textures in the feed sample. Since the main concern of this study is sulfide minerals, we mostly identified the type of these minerals and noted their physical appearance. Chalcopyrite and pyrrhotite were found within sphalerite, and the gangue mineral, pyroxene, was included with the host sphalerite (Figure $3 a, b)$. The particle sizes of chalcopyrite and galena inside sphalerite were in the approximate range of 10-20 $\mu \mathrm{m}$, which correspond to very fine particles, and it was difficult to liberate them from the host sphalerite by crushing and grinding (Figure 3c,d). In particular, some sphalerite was surrounded by pyrite, as shown in Figure 3d.

To analyze the elemental composition of sphalerite, SEM-EDS analysis was conducted; the results are shown in Figure 4 and Table 3. The zinc and iron concentrations of sphalerite were about 43 and $11 \mathrm{wt} \%$, respectively. This means that even a region that appears relatively pure in a microscope image can contain a considerable amount of iron, and if sphalerite could be successfully recovered by various separation methods, the zinc concentrate could exhibit a high iron content. Therefore, the high iron content of the feed sample (Table 1) can be explained by the iron-rich sphalerite and the presence of iron-bearing minerals such as pyrrhotite and pyrite.

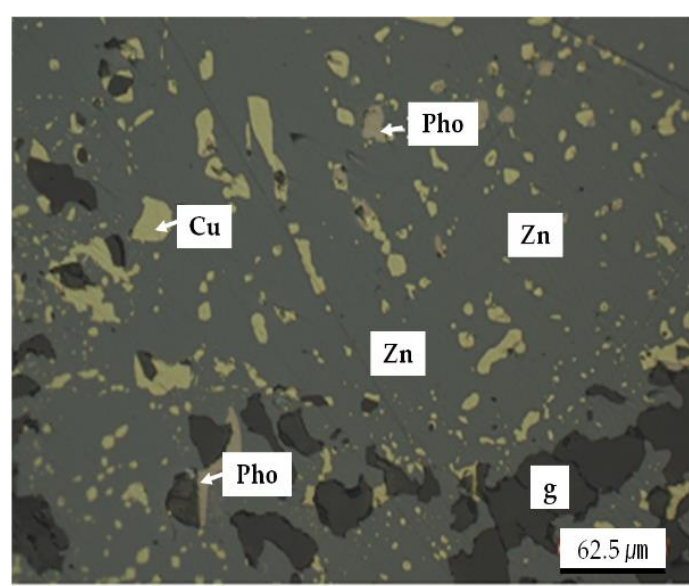

(a)

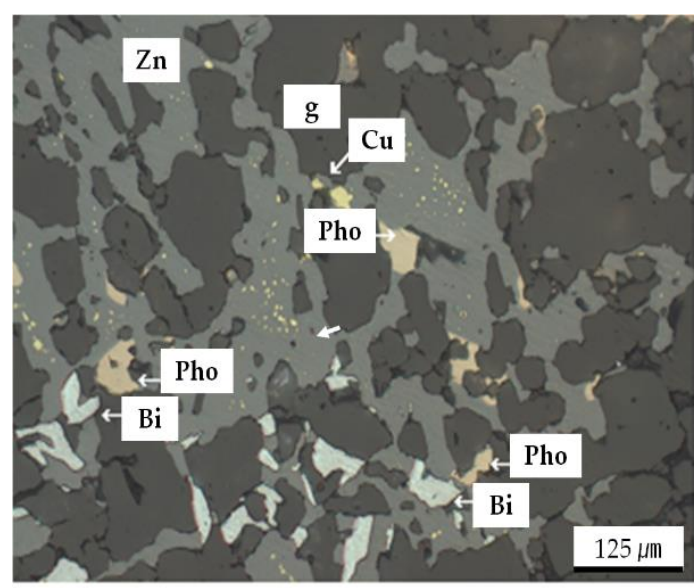

(b)

Figure 3. Cont. 


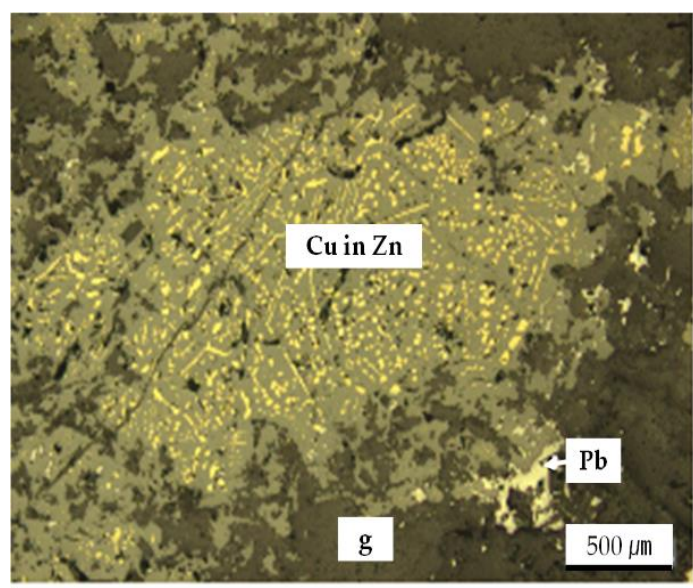

(c)

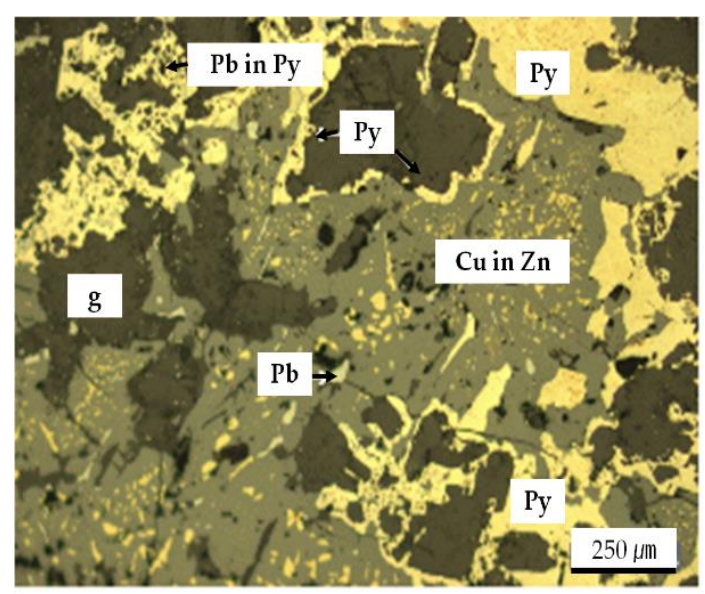

(d)

Figure 3. Images of ore texture in various thin sections of the feed sample: (a) $400 \times$; (b) $200 \times$; (c) $50 \times$; (d) $100 \times$. (Abbreviations: Cu, chalcopyrite; Zn, sphalerite; Pho, pyrrhotite; Pb, galena; Bi, bismuth; g, pyroxene; Py, pyrite).

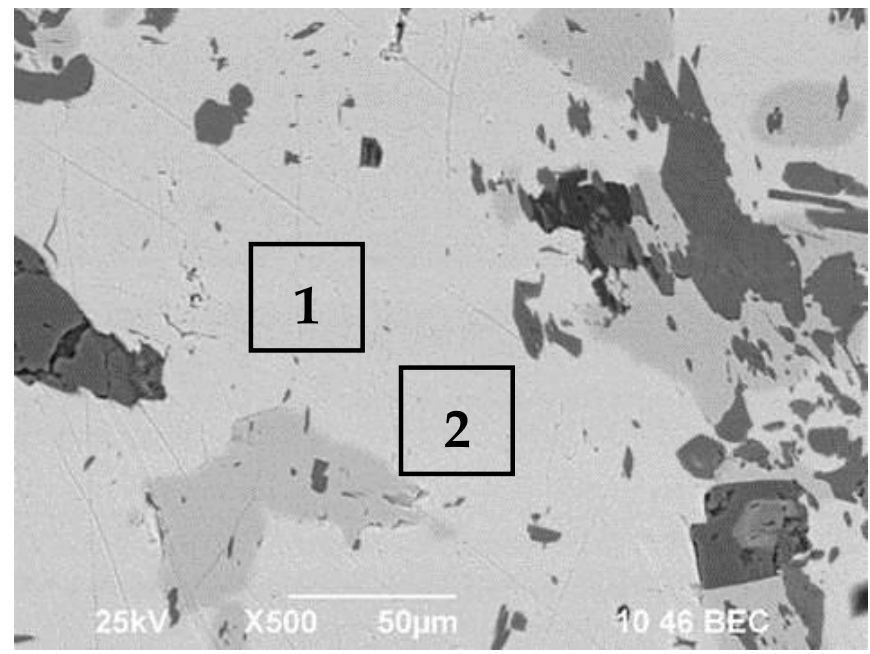

Figure 4. Surface image of sphalerite obtained by scanning electron microscopy (SEM) and locations to be analyzed by energy dispersive X-ray spectroscopy (EDS).

Table 3. Energy dispersive X-ray spectroscopy (EDS) analysis results of the locations shown in Figure 4.

\begin{tabular}{cccc}
\hline Location & & $\mathbf{1}$ & $\mathbf{2}$ \\
\hline & $\mathrm{S}$ & 46.15 & 45.37 \\
Elemental composition (wt \%) & $\mathrm{Fe}$ & 10.97 & 10.99 \\
& $\mathrm{Zn}$ & 42.88 & 43.64 \\
\hline
\end{tabular}

\subsection{Using Gravity Separation for Pre-Concentration}

To pre-concentrate valuable metallic minerals before the flotation process, various separation methods were applied to the feed sample. Since the density of a metallic mineral in this sample (sphalerite: $3.9-4.2 \mathrm{~g} / \mathrm{cm}^{3}$; galena: $7.2-7.6 \mathrm{~g} / \mathrm{cm}^{3}$; chalcopyrite: $4.1-4.3 \mathrm{~g} / \mathrm{cm}^{3}$; and pyrrhotite: $4.6 \mathrm{~g} / \mathrm{cm}^{3}$ ) was high when compared to that of a non-metallic mineral, density or gravity separation was expected to yield good separation results. To confirm the feasibility of using gravity separation for pre-concentration, a gravity-separation test was conducted using a shaking table. Contrary to expectation, both the grade and recovery of the concentrate were poor even for the best separation 
performance shown in Table 4 for the test conducted under optimal operation conditions. The recovery of every target element mainly occurred in the tailing and slime fractions owing to the high concentration of target elements among the particles with small size, as shown in Table 1. As a result, even though a metallic mineral had a high density when compared to non-metallic gangue minerals, it was not easy to apply a gravity separation method, such as a shaking table, for pre-concentration of metallic minerals in the feed sample. In addition, because pyroxene-group minerals, which have a high density, were present as non-metallic gangue minerals in this sample, the grade of the concentrate was not greatly improved.

Table 4. Results of gravity separation using a shaking table. (Angle of shaking table: $2.5^{\circ}$; amplitude: $1.5 \mathrm{~mm}$; water-flow rate: $10 \mathrm{~L} / \mathrm{min}$; frequency: $300 \mathrm{rpm}$ ).

\begin{tabular}{|c|c|c|c|c|c|c|c|c|c|}
\hline & \multirow{2}{*}{ Yield (wt \%) } & \multicolumn{2}{|c|}{$\mathbf{F e}$} & \multicolumn{2}{|c|}{ Zn } & \multicolumn{2}{|c|}{$\mathrm{Pb}$} & \multicolumn{2}{|c|}{$\mathrm{Cu}$} \\
\hline & & ${ }^{1}$ G (\%) & ${ }^{2} \operatorname{Re}(\%)$ & G (\%) & $\operatorname{Re}(\%)$ & G (\%) & $\operatorname{Re}(\%)$ & G (\%) & $\operatorname{Re}(\%)$ \\
\hline Concentrate & 4.31 & 29.3 & 5.8 & 17.8 & 10.2 & 0.82 & 18.1 & 0.39 & 10.5 \\
\hline Middling & 10.74 & 21.9 & 10.8 & 10.2 & 14.6 & 0.11 & 5.9 & 0.20 & 13.4 \\
\hline Tailing & 65.61 & 14.3 & 42.9 & 3.2 & 28.0 & 0.06 & 20.1 & 0.07 & 27.0 \\
\hline Slime & 19.35 & 13.5 & 40.5 & 5.4 & 47.2 & 0.17 & 55.9 & 0.12 & 49.1 \\
\hline
\end{tabular}

\subsection{Using Magnetic Separation for Pre-Concentration}

Next, the feasibility of using magnetic separation for pre-concentration of metallic minerals was investigated. Various minerals in the feed sample, such as pyrrhotite, iron-rich sphalerite, and gangue minerals, were expected to show different responses to the magnetic-separation process. If iron-rich sphalerite was separated from other minerals, the effectiveness of pre-concentration would be manifested as a significant mass reduction for the next stage. As mentioned in Section 2.2, the threshold particle size of the feed sample was adjusted on the basis of the maximum size, and only the coarse fraction (consisting of particles larger than $74 \mu \mathrm{m}$ ) was fed to the dry magnetic separation process. Owing to the low efficiency of separating the remaining fine particles with sizes below $74 \mu \mathrm{m}$ in the dry magnetic-separation, direct migration of these fine particles to the next process was considered.

Figure 5 shows the grade of target elements of each magnetic product as a function of the magnetic intensity for particles of various sizes. Naturally, the iron content was the highest in the products extracted at $0.2 \mathrm{~T}$ from particles of all sizes, and the iron content did not change much $(\approx 10 \%)$ in the products extracted at other magnetic intensities. The iron content of $0.2 \mathrm{~T}$ magnetic extracts increased as the maximum size of feed-sample particles decreased owing to the increased degree of liberation. These $0.2 \mathrm{~T}$ magnetic extracts mainly consisted of the iron-bearing ferromagnetic mineral, pyrrhotite, and some unliberated minerals, which accounted for the low iron content when compared to the theoretical iron content of pyrrhotite.

High concentrations of zinc were expected in the 0.4-0.6 T magnetic products owing to the magnetic property of iron-rich sphalerite. However, high concentrations of zinc were also detected in products extracted at $0.85 \mathrm{~T}$ and higher, especially those extracted from feed-sample particles measuring $0.3 \mathrm{~mm}$. This was probably due to the relatively pure sphalerite, which did not contain iron. As a result, the zinc content was high in products extracted at magnetic intensities below $0.6 \mathrm{~T}$ and above $0.85 \mathrm{~T}$, and the zinc content was very low $(\approx 1.5 \%)$ in magnetic products extracted at magnetic intensities in the range of $0.6-0.85 \mathrm{~T}$. The grade of lead was slightly low in the products extracted at $<0.6 \mathrm{~T}$, and the variations in both copper and lead content showed trends similar to that of the zinc content, as shown in Figure 5. 

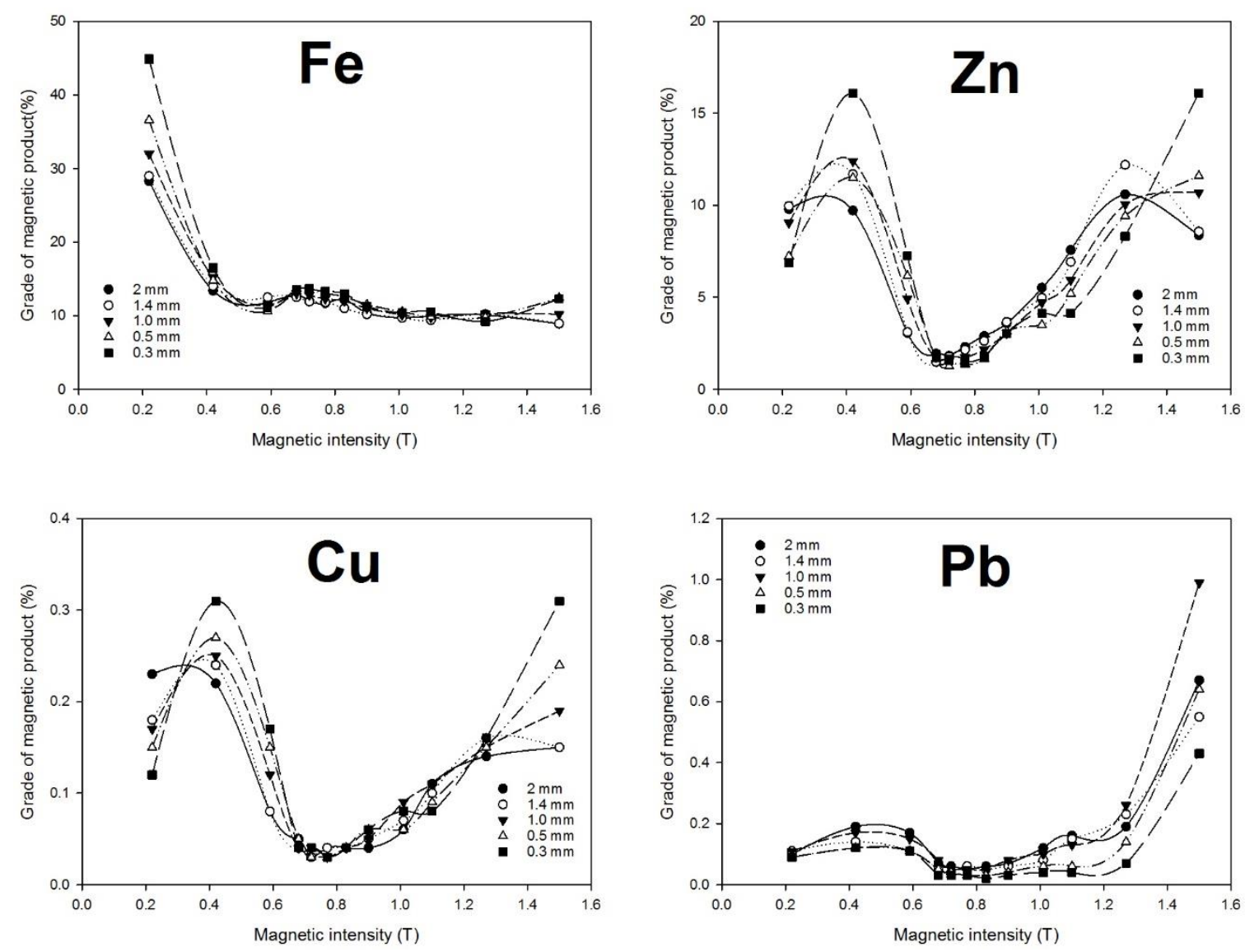

Figure 5. Grade of target elements in magnetic products that were extracted sequentially at low magnetic intensity and maximum feed-sample particle size.

The magnetic separation results of this study are in good agreement with those of previous studies on the magnetic susceptibility of sulfide minerals [22-24]. Gaudin and Spedden found that sphalerite (marmatite) showed a wide range of magnetic susceptibility as a function of the iron content [22], a trend that was also observed by Keys et al. [23]. The varying grade of elements recovered at different magnetic intensities, represented by the results shown in Figure 5, was the result of different iron concentrations in the sphalerite; these results confirmed the finding of previous studies. The iron-rich sphalerite was recovered at a magnetic intensity of around $0.4 \mathrm{~T}$, and relatively pure sphalerite was recovered at high magnetic intensity above $1.2 \mathrm{~T}$.

As can be seen in Figure 3, fine chalcopyrite and galena particles exhibited behavior similar to that of sphalerite because of insufficient liberation during the crushing stage. However, the magnetic susceptibility of chalcopyrite and galena are also one of the factors that determined the outcome of this separation test. According to the study of Gaudin and Spedden, galena is classified as sulfide minerals with low magnetic susceptibility, and it is not sufficiently recovered even at high magnetic intensity [22]. Similar separation trends were observed for galena in this study. As shown in Figure 5, unlike zinc and copper, the grade of lead was only high at high magnetic intensity. According to a study by Jirestig, sphalerite and chalcopyrite were recovered at similar magnetic intensity from a copper-lead flotation concentrate [24]. This is one of the reasons why the grade of zinc and copper are similar in this study as a function of magnetic intensity.

According to the results shown in Figure 5, the magnetic products could be divided into three ranges: $0.6 \mathrm{~T}$ magnetic products, $0.6 \mathrm{~T}$ non-magnetic/0.85 $\mathrm{T}$ magnetic products, and $0.85 \mathrm{~T}$ non-magnetic products; the average grade of each element in these products is shown in Figure 6. It was confirmed that the grade of all target elements in the medium-magnetic-intensity range $(0.6 \mathrm{~T}$ 
non-magnetic/0.85 T magnetic products) was reduced, whereas the grade of other products was enhanced when compared with the grade of these elements in the feed sample regardless of particle size. Therefore, if the products extracted at medium magnetic intensity with low grade were separated, they would demonstrate the effect of pre-concentration by dry magnetic separation.

The next consideration for magnetic separation was the particle size of the feed sample. Although there were no significant differences in the grades of target elements with variations in the maximum particle size, the recovery and the yield varied greatly depending on the particle size. Moreover, since the dry magnetic-separation process is not designed to produce the final concentrate, the recovery and the yield should be considered in order to ensure the overall economic efficiency. It is obvious that a high mass fraction and a low loss ratio of target elements to be removed from the sample are more advantageous for the overall process. Figure 7 shows the mass fraction of the medium-magnetic-intensity product and the loss ratio of target elements as functions of the maximum feed-sample particle size. The mass fraction of the medium-magnetic-intensity products was $28.3 \%$ when the maximum particle size was $0.3 \mathrm{~mm}$, and it increased to about $45-48 \%$ as the particle size increased to $1 \mathrm{~mm}$ or higher. As the particle size increased, the loss ratio of target elements increased with increases in mass fraction of the medium-magnetic-intensity products. When the maximum particle size reached and exceeded $1.4 \mathrm{~mm}$, the loss ratio of target elements, especially that of lead, was high. Therefore, based on the mass fraction and loss ratio of the target elements, it can be concluded that the separation efficiency was the highest when the maximum particle size was $1 \mathrm{~mm}$.
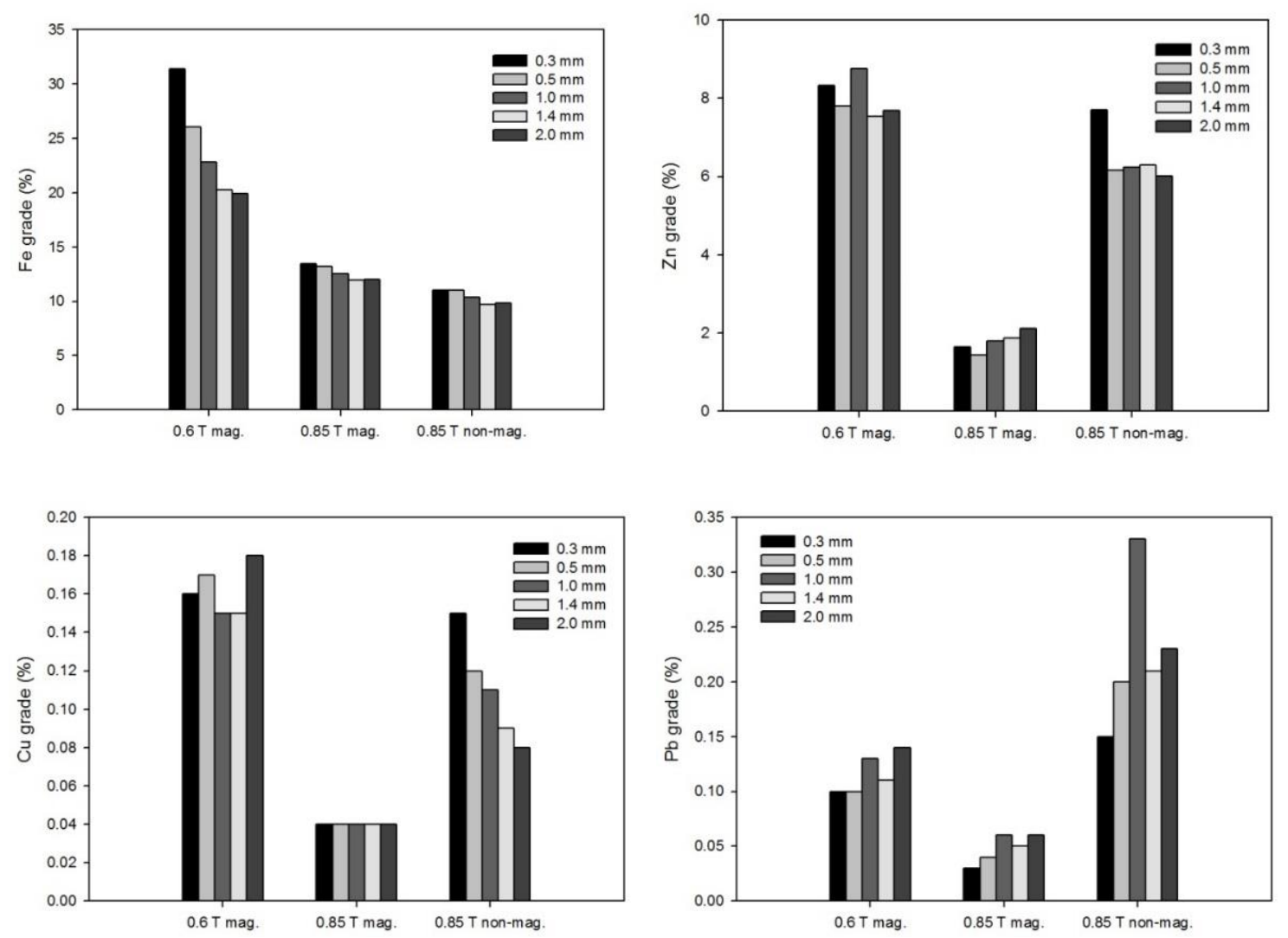

Figure 6. Grade of elements as a function of the magnetic intensity during the separation process. (Abbreviations: mag., magnetic; non-mag., non-magnetic). 


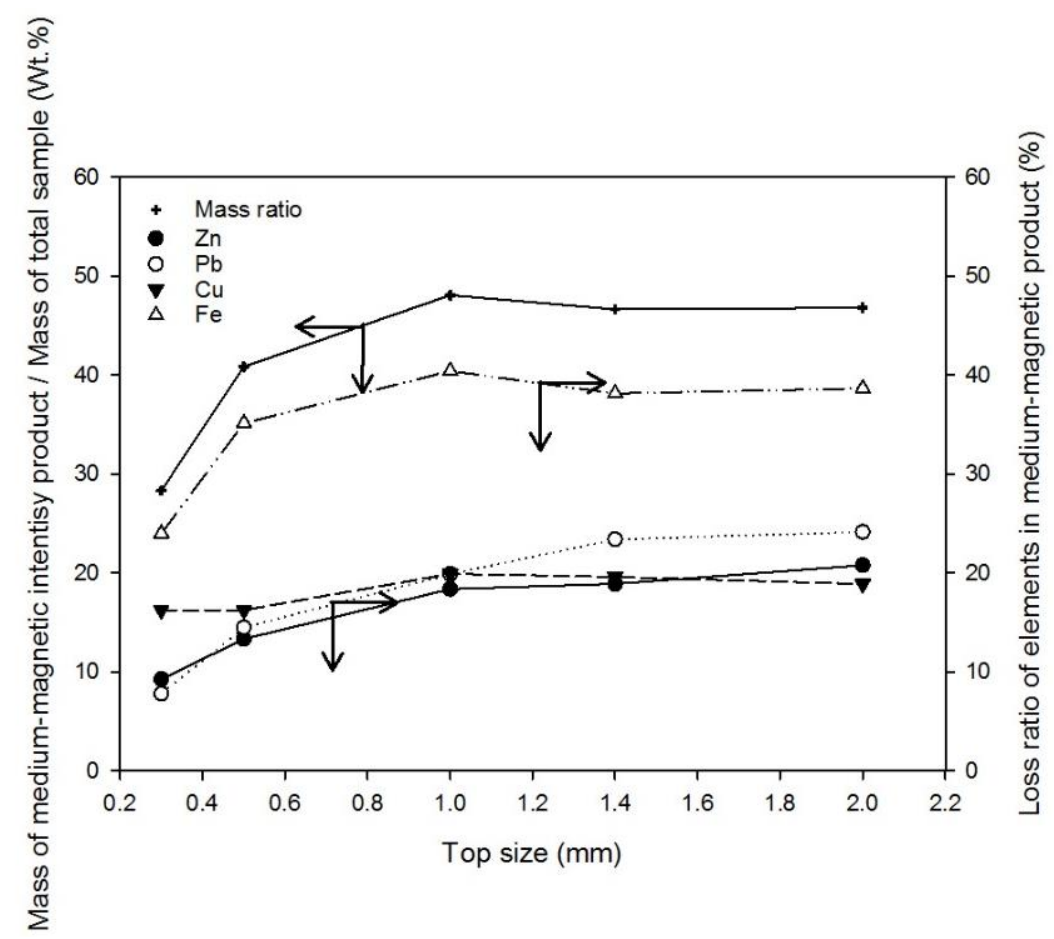

Figure 7. Mass fraction (wt \%) of products extracted at medium magnetic intensity $(0.6 \mathrm{~T}$ non-magnetic/0.85 T magnetic products) and loss ratio of target elements as functions of maximum size of feed-sample particles.

\subsection{Pre-Concentration Process of Sphalerite}

Using the above separation results, a pre-concentration process of $\mathrm{Pb}-\mathrm{Zn}$ deposits was developed; a flowchart of the process is shown in Figure 8. First, the sample is to be crushed using a jaw crusher and a cone crusher, and then screened to limit the maximum particle size to $1 \mathrm{~mm}$. The portion of fine particles with sizes below $74 \mu \mathrm{m}$ should be transferred directly to the flotation process owing to the low separation efficiency of these particles in the dry magnetic-separation process. The coarse portion of particles with sizes above $74 \mu \mathrm{m}$ should be fed to the dry magnetic-separation process, and the paramagnetic products ( $0.85 \mathrm{~T}$ magnetic products) are to be removed to reduce the mass fraction fed to the grinding process. The recovered ferromagnetic and diamagnetic products are to be ground and fed to the flotation process with the portion of fine particles. The pre-concentration test results are shown in Table 5. It can be seen that about $48.5 \%$ of the feed sample was removed in the pre-concentration stage, and $73-82 \%$ of the recovered target elements were moved to the next stage, i.e., flotation, for final concentration. Consequently, the grade of the target elements was enhanced from $4.88 \%$ to $8.1 \%$ for zinc, from $0.09 \%$ to $0.14 \%$ for lead, and from $0.09 \%$ to $0.12 \%$ for copper in the pre-concentration stage.

Table 5. Results of pre-concentration process of target elements.

\begin{tabular}{|c|c|c|c|c|c|c|c|c|c|}
\hline & \multirow{2}{*}{$\begin{array}{l}\text { Yield } \\
\text { (wt \%) }\end{array}$} & \multicolumn{2}{|c|}{$\mathrm{Fe}$} & \multicolumn{2}{|c|}{$\mathrm{Zn}$} & \multicolumn{2}{|c|}{$\mathrm{Pb}$} & \multicolumn{2}{|c|}{$\mathrm{Cu}$} \\
\hline & & ${ }^{1} \mathrm{G}(\%)$ & ${ }^{2} \operatorname{Re}(\%)$ & G (\%) & $\operatorname{Re}(\%)$ & G (\%) & $\operatorname{Re}(\%)$ & G (\%) & $\operatorname{Re}(\%)$ \\
\hline Ferromagnetic product & 23.1 & 27.5 & 36.3 & 8.93 & 42.0 & 0.12 & 31.0 & 0.15 & 42.3 \\
\hline Paramagnetic product & 48.5 & 14.3 & 39.6 & 1.55 & 15.3 & 0.04 & 21.1 & 0.04 & 22.5 \\
\hline Diamagnetic product & 15.2 & 12.7 & 11.1 & 7.3 & 22.7 & 0.16 & 27.3 & 0.10 & 17.5 \\
\hline Fine particle $(<74 \mu \mathrm{m})$ & 13.2 & 17.2 & 13.0 & 7.45 & 20.0 & 0.14 & 20.6 & 0.11 & 17.7 \\
\hline
\end{tabular}

${ }^{1}$ G: Grade; ${ }^{2}$ Re: Recovery. 


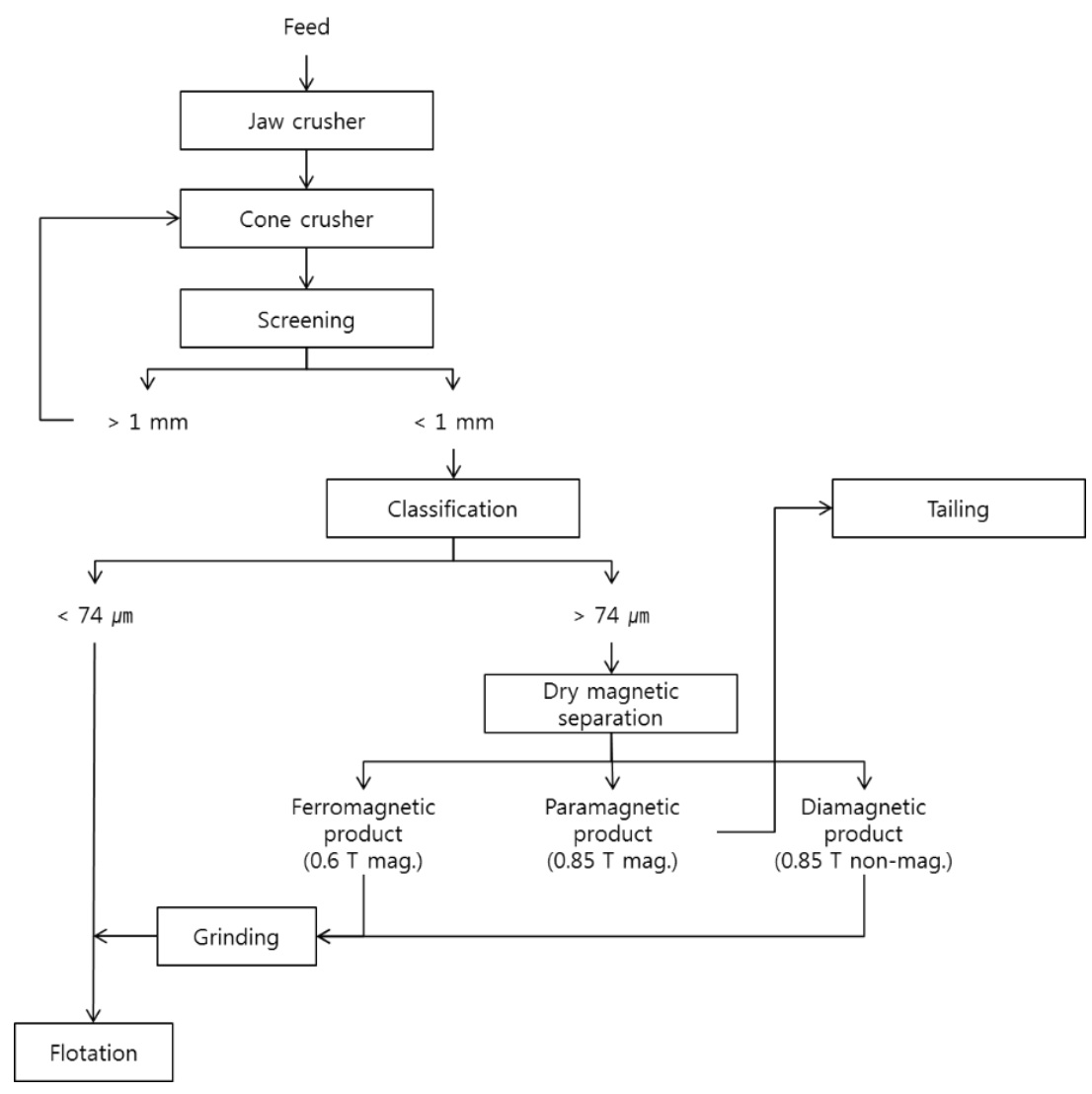

Figure 8. Flowchart of pre-concentration process using magnetic separation.

\section{Conclusions}

This paper describes the pre-concentration of $\mathrm{Pb}-\mathrm{Zn}$ deposits to reduce the mass of the load for subsequent processes, such as grinding and flotation. The conclusions of the study are as follows:

1. Sphalerite was the major sulfide mineral in the $\mathrm{Pb}-\mathrm{Zn}$ deposits obtained from the Gagok mine, and galena and chalcopyrite were not detected by XRD analysis owing to their low content. The grades of zinc, lead, copper, and iron were $4.88 \%, 0.09 \%, 0.09 \%$, and $15.3 \%$, respectively. The high content of iron in the feed sample can be attributed to the iron-rich sphalerite and ironbearing minerals, such as pyrrhotite.

2. Because target minerals (sphalerite, chalcopyrite, and galena) were concentrated by crushing in the portion of fine particles with sizes below $74 \mu \mathrm{m}$, the gravity separation method using a shaking table was not effective for this sample.

3. The dry magnetic separation experiment confirmed that concentrations of target elements were low in the products separated at intermediate magnetic intensity (0.6-0.85 $\mathrm{T}$ magnetic products), and the maximum particle size of $1 \mathrm{~mm}$ was appropriate from the viewpoint of mass reduction and loss ratio of target elements.

4. The pre-concentration process was developed using the results of magnetic separation. After the crushing stage, to limit the maximum particle size to $1 \mathrm{~mm}$, the portion of coarse particles with sizes above $74 \mu \mathrm{m}$ was fed to the magnetic separation process to remove low-grade target elements from the products extracted at intermediate magnetic intensity. About $48.5 \%$ of the feed sample was removed in the pre-concentration stage, and the grades of the target elements were enhanced: $65 \%$ for zinc, $55 \%$ for lead, and $33 \%$ for copper. Consequently, it is expected that the economic efficiency of the entire process will be significantly improved because the cost of grinding and flotation can be greatly reduced by removing the low-grade fraction of separated 
products in the pre-concentration stage. However, it is difficult to estimate the process costs from a simple flowchart. Generally speaking, the grinding and flotation process account for more than $50 \%$ of the total process cost. Therefore, cost saving of $20 \%$ or higher can be expected for the entire process by adopting the pre-concentration process.

Author Contributions: S.J. designed and performed the experiment and wrote the paper, and K.K. analyzed the date and wrote the paper.

Funding: This research was supported by the Convergence Research Project (CRC-15-06-KIGAM) funded by the National Research Council of Science and Technology (NST)

Conflicts of Interest: The authors declare no conflict of interest.

\section{References}

1. Fuerstenau, M.C.; Flotation, A.M. Gaudin Memorial Volume 2; American Institute of Mining, Metallurgical and Petroleum Engineers: New York, NY, USA, 1976; pp. 1029-1231.

2. Gómez, F.L.; Sierra, J.R.; Carcedo, F.G.; Garcia, F.M.; Garcia, J.M. Influence of ultrafine grain size in differential flotation of galena and sphalerite. Int. J. Miner. Process. 1986, 17, 303-316. [CrossRef]

3. Sehlotho, N.; Sindane, Z.; Bryson, M.; Lindvelt, L. Flowsheet development for selective Cu-Pb-Zn recovery at Rosh Pinah concentrator. Miner. Eng. 2018, 122, 10-16. [CrossRef]

4. Forssberg, K.E.; Subrahmanyam, T.; Nilsson, L.K. Influence of grinding method on complex sulphide ore flotation: A pilot plant study. Int. J. Miner. Process. 1993, 38, 157-175. [CrossRef]

5. Mehrabani, J.; Noaparast, M.; Mousavi, S.; Dehghan, R.; Ghorbani, A. Process optimization and modelling of sphalerite flotation from a low-grade $\mathrm{Zn}-\mathrm{Pb}$ ore using response surface methodology. Sep. Purif. Technol. 2010, 72, 242-249. [CrossRef]

6. Pérez-Garibay, R.; Ramírez-Aguilera, N.; Bouchard, J.; Rubio, J. Froth flotation of sphalerite: Collector concentration, gas dispersion and particle size effects. Miner. Eng. 2014, 57, 72-78. [CrossRef]

7. Fosu, S.; Skinner, W.; Zanin, M. Detachment of coarse composite sphalerite particles from bubbles in flotation: Influence of xanthate collector type and concentration. Miner. Eng. 2015, 71, 73-84. [CrossRef]

8. Wang, J.; Xie, L.; Liu, Q.; Zeng, H. Effects of salinity on xanthate adsorption on sphalerite and bubble-sphalerite interactions. Miner. Eng. 2015, 77, 34-41. [CrossRef]

9. Ejtemaei, M.; Nguyen, A.V. A comparative study of the attachment of air bubbles onto sphalerite and pyrite surfaces activated by copper sulphate. Miner. Eng. 2017, 109, 14-20. [CrossRef]

10. Finkelstein, N. The activation of sulphide minerals for flotation: A review. Int. J. Miner. Process. 1997, 52, 81-120. [CrossRef]

11. Laskowski, J.; Liu, Q.; Zhan, Y. Sphalerite activation: Flotation and electrokinetic studies. Miner. Eng. 1997, 10, 787-802. [CrossRef]

12. Rao, S.; Nesset, J.; Finch, J. Activation of sphalerite by $\mathrm{Cu}$ ions produced by cyanide action on chalcopyrite. Miner. Eng. 2011, 24, 1025-1027. [CrossRef]

13. Albrecht, T.; Addai-Mensah, J.; Fornasiero, D. Critical copper concentration in sphalerite flotation: Effect of temperature and collector. Int. J. Miner. Process. 2016, 146, 15-22. [CrossRef]

14. Yang, B.; Tong, X.; Lan, Z.; Cui, Y.; Xie, X. Influence of the interaction between sphalerite and pyrite on the copper activation of sphalerite. Minerals 2018, 8, 16. [CrossRef]

15. Dávila-Pulido, G.; Uribe-Salas, A.; Espinosa-Gómez, R. Comparison of the depressant action of sulfite and metabisulfite for Cu-activated sphalerite. Int. J. Miner. Process. 2011, 101, 71-74. [CrossRef]

16. Huang, P.; Cao, M.; Liu, Q. Selective depression of sphalerite by chitosan in differential $\mathrm{Pb}-\mathrm{Zn}$ flotation. Int. J. Miner. Process. 2013, 122, 29-35. [CrossRef]

17. Liu, J.; Wang, Y.; Luo, D.; Zeng, Y. Use of $\mathrm{ZnSO}_{4}$ and SDD mixture as sphalerite depressant in copper flotation. Miner. Eng. 2018, 121, 31-38. [CrossRef]

18. Solecki, J.; Komosa, A.; Szczypa, J. Copper ion activation of synthetic sphalerites with various iron contents. Int. J. Miner. Process. 1979, 6, 221-228. [CrossRef]

19. Buckley, A.; Woods, R.; Wouterlood, H. An XPS investigation of the surface of natural sphalerites under flotation-related conditions. Int. J. Miner. Process. 1989, 26, 29-49. [CrossRef] 
20. Boulton, A.; Fornasiero, D.; Ralston, J. Effect of iron content in sphalerite on flotation. Miner. Eng. 2005, 18, 1120-1122. [CrossRef]

21. Tong, X.; Song, S.; He, J.; Rao, F.; Lopez-Valdivieso, A. Activation of high-iron marmatite in froth flotation by ammoniacal copper (ii) solution. Miner. Eng. 2007, 20, 259-263. [CrossRef]

22. Gaudin, A.; Spedden, H. Magnetic separation of sulphide minerals. Trans. Am. Inst. Min. Metall. Eng. 1943, 153, 563-575.

23. Keys, J.; Horwood, J.; Baleshta, T.; Cabri, L.; Harris, D. Iron-iron interaction in iron-containing zinc sulphide. Can. Miner. 1968, 9, 453-467.

24. Jirestig, J.; Forssberg, E. Magnetic characterization of sulphide ores: Examples from Sweden. Phys. Sep. Sci. Eng. 1992, 4, 31-45. [CrossRef]

25. Pearce, C.I.; Pattrick, R.A.; Vaughan, D.J. Electrical and magnetic properties of sulfides. Rev. Miner. Geochem. 2006, 61, 127-180. [CrossRef]

26. Yun, S.; Einaudi, M.T. Zinc-lead skarns of the Yeonhwa-Ulchin district, South Korea. Econ. Geol. 1982, 77, 1013-1032. [CrossRef]

(C) 2018 by the authors. Licensee MDPI, Basel, Switzerland. This article is an open access article distributed under the terms and conditions of the Creative Commons Attribution (CC BY) license (http:/ / creativecommons.org/licenses/by/4.0/). 